\title{
Viral and serological kinetics in Zika virus- infected patients in South Korea
}

Young Eui Jeong ${ }^{1 \dagger}$, Go-Woon Cha ${ }^{1 \dagger}$, Jung Eun Cho ${ }^{1}$, Eun Ju Lee ${ }^{1}$, Youngmee Jee ${ }^{2}$ and Won-Ja Lee ${ }^{1 *}$

\begin{abstract}
Zika virus is a mosquito-borne flavivirus that causes clinical symptoms similar to those observed in dengue and chikungunya virus infections. The Korea Centers for Disease Control and Prevention initiated laboratory testing using a real-time reverse transcription-polymerase chain reaction in January 2016. More than 1,000 suspected cases of infection were tested and nine were confirmed as imported cases of Zika virus infection from January to July 2016. The travel destinations of the infected individuals were Brazil, Philippines, Viet Nam, Guatemala, Puerto Rico, and the Dominican Republic. Phylogenetic analysis based on the partial envelope gene indicated that the viruses belonged to the Asian genotype circulating in South America. We further investigated the duration for which the viral RNA and virus-specific antibodies were detectable after the symptom onset. After the day of symptom onset, Zika virus was detectable until 6 days in serum, 14 days in urine and saliva, and 58 days in semen. Immunoglobulin $M$ against Zika virus was detected as early as 2 days after the symptom onset and was maintained at these levels until 41 days, whereas Immunoglobulin $\mathrm{G}$ was detectable from 8 days after the symptom onset and was maintained until 52 days. These findings would help diagnostic laboratories improve their testing programs for Zika virus infection.
\end{abstract}

Keywords: Zika virus, Chikungunya virus, Dengue virus, Reverse transcription-polymerase chain reaction, Enzyme-Linked Immunosorbent Assay, Phylogenetic analysis

\section{Findings}

Zika virus is a mosquito-borne virus belonging to the genus Flavivirus in the family Flaviviridae. The virus was first isolated from a sentinel monkey in the Zika forest in Africa in 1947 [1]. It causes mild symptoms such as fever, rash, myalgia, arthralgia, and retro-orbital eye pain, which are similar to those caused by dengue and chikungunya virus infection [2]. The transmission of the virus was limited to the African continent until 2007, when an outbreak occurred in Yap Island of Micronesia [3]. Since then, the virus has disseminated rapidly to Asia and South America. In February 2016, the World Health Organization declared Zika virus infection associated with microcephaly as a Public Health Emergency of International Concern.

The Korea Centers for Disease Control and Prevention (KCDC) designated Zika virus infection as a notifiable

\footnotetext{
*Correspondence: leewonja@gmail.com

${ }^{\dagger}$ Equal contributors

'Division of Arboviruses, National Institute of Health, Korea Centers for Disease Control and Prevention, 187 Osongsaengmyeong 2-ro, Osong-yeup, Cheongju-si, Chungbuk-do 28159, South Korea

Full list of author information is available at the end of the article
}

disease and initiated laboratory testing for this disease in January 2016. All persons who had travelled to countries with active Zika virus transmission in the 2 weeks prior to the onset of symptoms were suspected to be infected with the Zika virus, and laboratory testing was recommended. Sexual partners of persons with suspected or confirmed Zika virus infection were also recommended to undergo laboratory testing. The KCDC used a custom-made real-time reverse transcription-polymerase chain reaction (qRT-PCR) kit, namely the genesig Zika Virus polyprotein standard kit (PrimerDesign Ltd., UK) for detection of viral RNA in various types of samples. To detect the virus, viral RNA was extracted from 140 $\mu \mathrm{L}$ of sample using the QIAamp Viral RNA Mini kit (QIAGEN, Hilden, Germany) according to the manufacturer's instructions. No treatment, such as concentration or filtration of the sample, was done prior to RNA extraction. The contents of genesig Zika Virus polyprotein standard kit are as follows: virus specific primer/probe mixture, positive control template (in vitro-transcribed RNA transcript), nuclease-free water, and $2 \times$ qRT-PCR Mastermix. Sequences of the primers and probe were 
not disclosed according to the company's policy. The qRT-PCR mixture consisted of $10 \mu \mathrm{L} 2 \times$ qRT-PCR Mastermix, $1 \mu \mathrm{L}$ primer/probe mixture, $4 \mu \mathrm{L}$ nucleasefree water, and $5 \mu \mathrm{L}$ RNA sample. Thermal cycling conditions for reverse transcription were as follows: $55^{\circ} \mathrm{C}$ for $10 \mathrm{~min}$, enzyme activation at $95^{\circ} \mathrm{C}$ for $2 \mathrm{~min}$ followed by 45 cycles of PCR $\left(95^{\circ} \mathrm{C}\right.$ for $10 \mathrm{~s}, 6{ }^{\circ} \mathrm{C}$ for $\left.60 \mathrm{~s}\right)$. The amplification was performed using the ABI StepOne Plus or 7500 instrument (Applied Biosystems, Foster City, CA, USA). A sample with a threshold cycle $\left(\mathrm{C}_{\mathrm{T}}\right)$ number $\leq 40$ was considered to be positive for Zika virus infection. We additionally performed qRT-PCR according to the protocol described by Lanciotti et al. (1086/1163/1108FAM set), as a reference method [3].

We conducted RT-PCR assay to obtain the DNA sequence of the partial envelope (E) gene from Zikapositive samples [4]. The composition of the reaction mixture $(25 \mu \mathrm{L})$ was $5 \mu \mathrm{L} 5 \times$ QIAGEN One Step RTPCR buffer, $1 \mu \mathrm{L}$ dNTP mix, $1.5 \mu \mathrm{L}$ each of the forward (ENV_F, GCT GGD GCR GAC ACH GGR ACT; $10 \mu \mathrm{M}$ stock) and reverse primers (ENV_R, RTC YAC YGC CAT YTG GRC TG; $10 \mu \mathrm{M}$ stock), $1 \mu \mathrm{L}$ One Step RTPCR Enzyme Mix, $10 \mu \mathrm{L}$ nuclease-free water, and $5 \mu \mathrm{L}$ RNA sample. The thermal profile for RT-PCR was as follows: reverse transcription at $50{ }^{\circ} \mathrm{C}$ for $30 \mathrm{~min}$, enzyme activation at $95{ }^{\circ} \mathrm{C}$ for $15 \mathrm{~min}$ followed by 40 cycles of PCR $\left(94{ }^{\circ} \mathrm{C}\right.$ for $20 \mathrm{~s}, 55^{\circ} \mathrm{C}$ for $20 \mathrm{~s}, 72{ }^{\circ} \mathrm{C}$ for $30 \mathrm{~s}$ ) and a final extension cycle at $72{ }^{\circ} \mathrm{C}$ for $3 \mathrm{~min}$. The positive products ( $\sim 365$ base pair, bp) were analyzed by electrophoresis using 1.5\% agarose gel, purified from the gels using the QIAquick gel extraction kit (QIAGEN), and sequenced using the ABI PRISM BigDye Terminator Cycle Sequencing kits and ABI 3730xl sequencer (Applied Biosystems). The resulting sequence files were compiled using the SeqMan program in the Lasergene software version 8.0 (DNASTAR, WI, USA) and final $340 \mathrm{bp}$ of $\mathrm{E}$ gene sequences were obtained. The sequence divergence ( $\mathrm{p}$-distance) among the $\mathrm{E}$ gene sequences was calculated using the Distance menu of the MEGA program (version 6.06). For phylogenetic analysis, $23 \mathrm{E}$ gene sequences of Zika virus deposited in the GenBank were selected and seven new sequences obtained in this study were added. A multiple alignment of the sequences was done by the ClustalW method in the MEGA software. Phylogenetic tree was constructed by neighbor-joining method using the substitution model of maximum composite likelihood. The reliability of the tree was assessed by bootstrap analysis (1,000 replicates).

We further investigated the duration for which the viral RNA was detectable in various specimens (serum, urine, saliva, and semen), as number of days after the symptom onset. Specimens were collected until 85 days after the symptom onset at 1-week intervals. We also conducted serological testing for serum samples to reveal the antibody kinetics in patients with Zika virus infection, using three commercial kits: Quantitative $\mathrm{Hu}$ man Zika Virus IgM ELISA kit (MyBioSource Inc., San Diego, CA, USA), Zika virus IgM/IgG Ab Rapid Test (Biocan Diagnostics Inc., Canada), and Anti-Zika Virus IgM/IgG ELISA (Euroimmun, Germany). Among the 3 kits, the performance of only Euroimmun ELISA kit (IgM sensitivity, 90.1\%; IgG sensitivity, 50\%) was previously reported [5]. Furthermore, the serological crossreactivity of Zika-positive serum with other flaviviruses, including dengue, Japanese encephalitis, and West Nile viruses, was investigated using DENV Detect IgM capture ELISA, JE Detect IgM capture ELISA, and West Nile Detect IgM capture ELISA (InBios, Seattle, WA, USA), respectively.

From January to July 2016, more than 1,000 suspected cases of Zika virus infection were tested and nine were confirmed as cases of imported Zika virus infection. The destinations of travel were Brazil (1 case), Philippines (3 cases), Viet Nam (2 cases), Guatemala (1 case), Puerto Rico (1 case), and the Dominican Republic (1 case). The mean time \pm standard deviation between the symptom onset and first sample collection was $3.6 \pm 2.1$ days (range, 0-6 days). The onset of symptoms was defined based on the memory of each patient and it was recorded by physicians Viral RNA was detected in urine samples of all 9 patients (100\%), but was detected in serum samples of only 3 out of the 9 patients (33.3\%) (Table 1). The viral RNA concentration ranged from 263 to 199,460 copies/mL according to sample type, collection date, and individuals. As for a serological test using

Table 1 Laboratory testing results of imported Zika cases in South Korea, from January to July $2016^{a}$

\begin{tabular}{|c|c|c|c|c|c|}
\hline \multirow{2}{*}{$\begin{array}{l}\text { Patient } \\
\text { code }\end{array}$} & \multirow{2}{*}{$\begin{array}{l}\text { Days (symptom } \\
\text { onset to sampling) }\end{array}$} & \multicolumn{2}{|c|}{ qRT-PCR (copies/mL) } & \multicolumn{2}{|c|}{ ELISA $^{c}$} \\
\hline & & Serum & Urine & $\lg M$ & $\lg G$ \\
\hline 1 & 5 (serum), 6 (urine) & $+(1,347)$ & $+(39,034)$ & - & - \\
\hline 2 & 3 & - & $+(762)$ & - & - \\
\hline 3 & 3 & - & $+(2,313)$ & - & - \\
\hline 4 & 2 & - & $+(263)$ & + & - \\
\hline 5 & 0 & $+(588)$ & $+(199,460)$ & - & - \\
\hline 6 & 4 & - & $+(3,049)$ & + & - \\
\hline 7 & 6 & - & $+(24,385)$ & + & - \\
\hline 8 & 6 & $+(5,326)$ & $+(934)$ & - & - \\
\hline 9 & IU & NT & $+(6,063)$ & NT & NT \\
\hline
\end{tabular}

a $/ U$ information unavailable, $N T$ not tested because specimen was not available, - negative, + positive

${ }^{b}$ qRT-PCR was performed using genesig Zika virus polyprotein standard kit (PrimerDesign Ltd., UK). Virus titer was estimated by testing pre-quantitated dilution of viral RNA transcripts (provided in the kit) and standard curve calculation generated by the ABI 7500 instrument (Applied Biosystems) 'Data were obtained using Anti-Zika Virus IgM/lgG ELISA kits

(Euroimmun, Germany) 
an ELISA kit, the acute-phase serum of only 3 of the 9 patients (33.3\%) was positive for IgM.

RT-PCR targeting the partial E gene was successfully for 7 of 9 cases (77.8\%). The sequence similarities between the seven samples were $97.4-99.7 \%$ and $99.1-$ $100 \%$ at the nucleotide and amino acid sequence levels, respectively (GenBank accession numbers, KY042039KY042045). Further, a phylogenetic tree based on the partial $E$ gene sequences obtained from different countries was constructed (Fig. 1). The result indicated that the viruses responsible for infection in the 7 cases belonged to the Asian genotype currently circulating in South America [6].

Although individual variation was observed and sample numbers were limited, the period over which viral RNA was detectable differed according to the sample type (Fig. 2). Overall, after the day of symptom onset, viral RNA was detectable until 6 days in serum, 14 days in urine and saliva, and 58 days in semen, respectively. In detail, viral RNA was detected only in 5 out of 10 $(50 \%)$ acute-phase serum specimens (within a week of onset) and the detection rate fell to zero $(0 / 10)$ in sera collected between 1 and 2 weeks following the symptom onset. However, viral RNA was detectable in all of the 9 $(100 \%)$ urine samples drawn within a week of onset, and the rate fell to $50 \%(5 / 10)$ in urine drawn between 1 and 2 weeks following the symptom onset. In case of saliva, viral RNA was detected in the 2 samples $(100 \%)$ drawn within a week of onset, and the detection rate fell to $50 \%(5 / 10)$ in the sample drawn between 1 and 2 weeks following the symptom onset. The results indicate that urine and saliva samples are preferable over serum samples, as they are obtained easily through painless procedures and show higher virus detection rates than those observed in serum samples. Our results are similar with those of previous reports describing the duration of viral RNA detection in different specimens [7-9]. The recovery of Zika virus was reported from urine and saliva as well as from serum and semen $[10,11]$. The viruses were isolated from 2 out of 9 patients by inoculating the RT-PCR positive specimens to mammalian cells (BHK-21, Vero, and LLC-MK2); these data will be reported in the near future.

The duration for which antibodies against Zika virus remain detectable in patient's serum has not yet been established. The humoral immune response to Zika virus after infection was investigated using commercial kits (ELISA and gold rapid test). Anti-Zika Virus IgM and IgG ELISA kits from Euroimmun Inc. (Germany) were successfully used for detection of anti-Zika virus

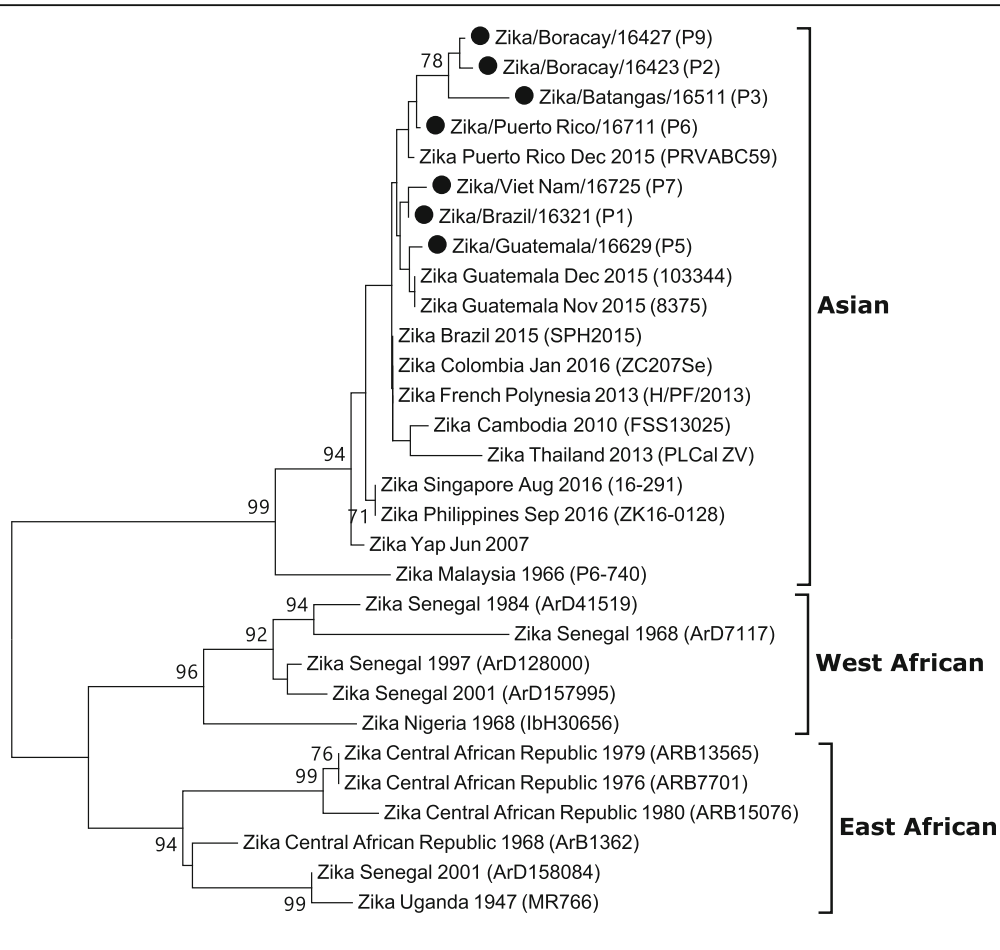

0.01

Fig. 1 Phylogenetic analysis of the Zika virus based on the partial envelope gene. The tree was constructed by the neighbor-joining method (substitution model: maximum composite likelihood) using MEGA 6 software. The percentage of bootstrap values is shown at each node (1,000 replications). Sequences of Zika viruses detected in this study are indicated as closed circles and the patient code is marked in the parenthesis. Zika virus genotypes are as defined previously [16] 

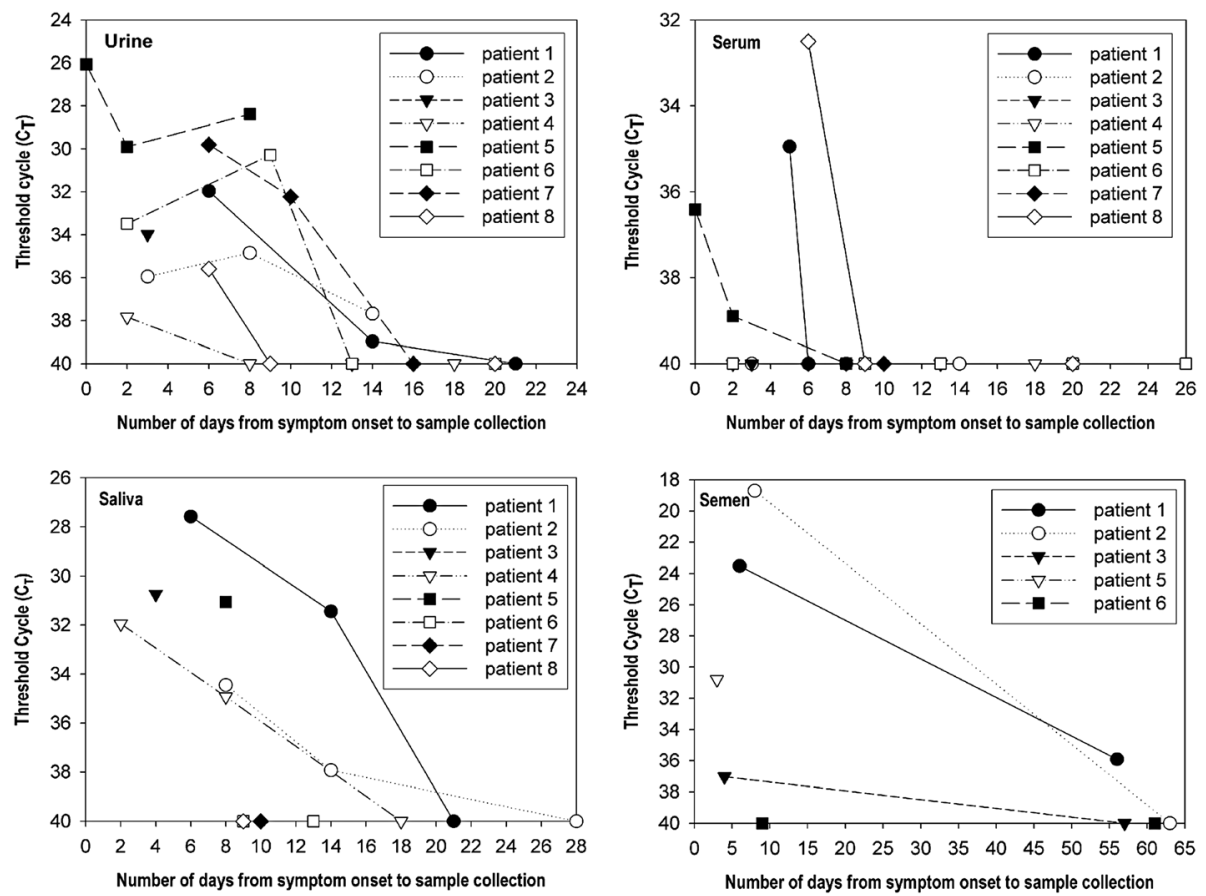

Fig. 2 Duration of detectability of Zika viral RNA in different specimens. qRT-PCR was performed using a commercial kit (PrimerDesign Ltd., UK) with serum, urine, saliva, and semen samples. A sample with a threshold cycle $\left(C_{T}\right)$ number $\leq 40$ was considered to be Zika-positive. In patient 3, the final collection of semen was performed at 86th day after the symptom onset and the result was negative. It was not presented for the sake of brevity

antibodies in 8 of the 9 (88.9\%) patients (Fig. 3). However, no positive results were obtained using the Quantitative Human Zika Virus IgM ELISA kit (MyBioSource Inc., Lot E160512AI) and Zika virus IgM/IgG Ab Rapid Test (Biocan Diagnostics Inc., Lot B1815C021616). It could be concluded that the latter two kits were unacceptable for Zika virus testing and require improvement in terms of sensitivity; this was the first evaluation report for the two kits. Using the Euroimmun ELISA kit, IgM against Zika virus was detected as early as 2 days after the symptom onset and IgG was detected from 8 days after the symptom onset (Fig. 3). Of the seven patients whose serum samples were reactive to ELISA and for whom the days of symptom onset available, IgM was detected in acute-phase sera drawn from 4 (57.1\%) patients, within 6 days post-onset. However, IgM was positive in all seven patients (100\%) from 8 days post-onset. The IgM and IgG were maintained at detectable levels until 41 days and 52 days after the symptom onset, respectively. It is well known that IgM against flaviviruses, including dengue, West Nile, and Japanese encephalitis viruses, as indicated by ELISA, persist for up to several
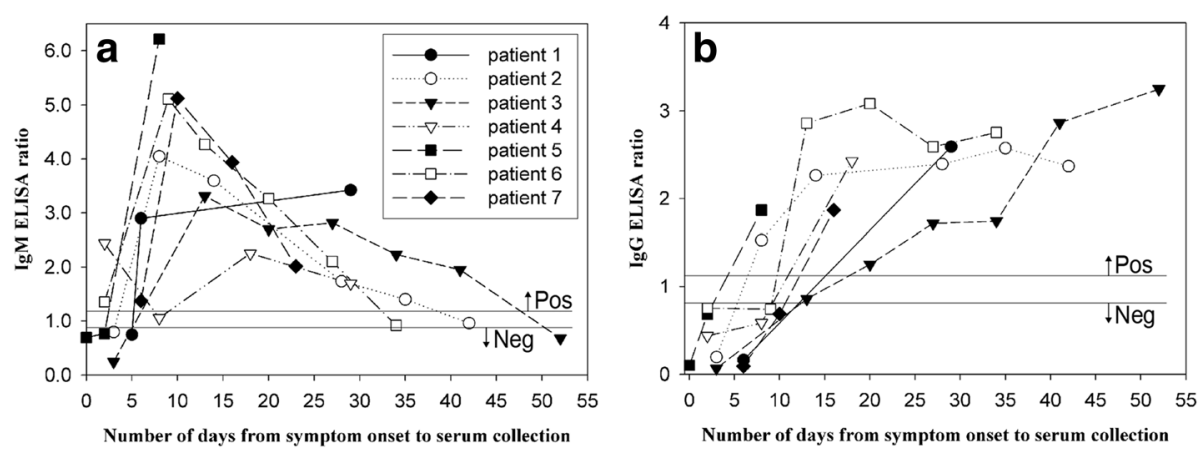

Fig. 3 Profile of IgM and IgG responses to Zika virus infection in human serum. ELISA was performed using Anti-Zika Virus IgM/lgG ELISA kits (Euroimmun, Germany). a IgM ELISA response, $\mathbf{b}$ IgG ELISA response; the different symbols represent each patient. Interpretation of the results was based on the ratio of optical density of the patient serum over the value of the calibrator, according to the manufacturer's instructions. Ratio $<0.8$ indicates a negative result, $0.8 \leq$ ratio $<1.1$ indicates a borderline result, and ratio $\geq 1.1$ indicates a positive result 
months and up to a year in the case IgG [12-14]. However, it was found that anti-Zika virus IgM antibody titer in patients 2, 3, and 6 fell to equivocal or negative levels at 42, 52, and 34 days post-onset (Fig. 3), respectively. The short duration of antibody detectability in those cases, as indicated by the Euroimmun ELISA, may be caused by the use of nonstructural protein 1 (NS 1) rather than $\mathrm{E}$ protein as a diagnostic marker. Further testing using other types of ELISA kits (e.g., ELISA with E protein as target) with a large sample size is required for elucidation of the kinetics of IgM and IgG responses to Zika virus infection in human serum.

The cross-reactivity of anti-Zika virus IgM antibody with other flaviviruses was investigated using flavivirusspecific ELISA kits. IgM cross-reactivity to other flaviviruses was shown in 2 of the 9 (22.2\%) confirmed patients. Serum of the patient 2 showed a positive result in West Nile ELISA, and serum of the patient 6 exhibited a positive result in all the ELISAs (West Nile, dengue, and Japanese encephalitis viruses). The results are consistent with those of the previous studies describing the high cross-reactivity in the flavivirus serology [15].

\section{Conclusions}

In conclusion, we reported 9 travel-associated Zika cases in South Korea between January - July 2016. We found that a custom-made qRT-PCR kit and Euroimmun Anti-Zika Virus IgM/IgG ELISA kit were acceptable for routine laboratory testing for Zika virus infection. Additionally, we described virus and antibody kinetics in cases of Zika virus infection using various sample types. These findings should enable diagnostic laboratories to improve their testing programs for Zika virus infection.

\footnotetext{
Abbreviations

bp: Base pair; C $C_{T}$ Threshold cycle; E: Envelope; ELISA: Enzyme-Linked Immunosorbent Assay; Ig: Immunoglobulin; KCDC: Korea Centers for Disease Control and Prevention; NS1: Nonstructural protein 1; RT-PCR: Reverse transcription-polymerase chain reaction
}

\section{Acknowledgements}

The authors thank Ms. Eun Kyoung Shin for her assistance with the production of graphics. We also thank Mr. Seung Hwan Shin, epidemiological investigator at the KCDC, for arranging sample collection and providing appropriate information.

\section{Funding}

This study was supported by funding from the Korea Centers for Disease Control and Prevention (4847-311-210-13, 4837-301-210-13). The funding agency had no role in study design, data collection and analysis, decision to publish, or preparation of the manuscript.

\section{Availability of data and materials}

Information regarding the E gene sequences of Zika virus detected in this study is available from GenBank under the following accession numbers: KY042039-KY042045.

\section{Authors' contributions}

YEJ set up the RT-PCR assays, performed experiments, analyzed the data, and wrote the manuscript. GWC performed experiments (RT-PCR and sequencing), analyzed the data, and prepared the phylogenetic tree. JEC and EL performed ELISA and analyzed the data. YJ reviewed the manuscript. WJL managed the diagnostic laboratory and reviewed the manuscript. All authors read and approved the final manuscript.

\section{Competing interests}

The authors declare that they have no competing interests.

\section{Consent for publication}

Not applicable.

\section{Ethics approval and consent to participate}

The laboratory testing for Zika virus infection was performed upon request by medical institutions in accordance with the Act on the Prevention and Control of Infectious Diseases. Seoul National University Hospital received written consent for sample collection from each patient with Zika virus infection and received approval from the ethical committee (H1605057761).

\section{Publisher's Note}

Springer Nature remains neutral with regard to jurisdictional claims in published maps and institutional affiliations.

\section{Author details}

'Division of Arboviruses, National Institute of Health, Korea Centers for Disease Control and Prevention, 187 Osongsaengmyeong 2-ro, Osong-yeup, Cheongju-si, Chungbuk-do 28159, South Korea. ${ }^{2}$ Korea Centers for Disease Control and Prevention, Cheongju-si 28159, Chungbuk-do, South Korea.

Received: 11 November 2016 Accepted: 28 March 2017

Published online: 07 April 2017

\section{References}

1. Kirya BG. A yellow fever epizootic in Zika forest, Uganda, during 1972: Part 1: Virus isolation and sentinel monkeys. Trans R Soc Trop Med Hyg. 1977;71:254-60.

2. Duffy MR, Chen TH, Hancock WT, Powers AM, Kool JL, Lanciotti RS, et al. Zika virus outbreak on Yap Island, Federated States of Micronesia. N Engl J Med. 2009;360:2536-43.

3. Lanciotti RS, Kosoy OL, Laven JJ, Velez JO, Lambert AJ, Johnson AJ, et al. Genetic and serologic properties of Zika virus associated with an epidemic, Yap State, Micronesia, 2007. Emerg Infect Dis. 2008;14:1232-9.

4. Faye O, Faye O, Dupressoir A, Weidmann M, Ndiaye M, Alpha SA. One-step RT-PCR for detection of Zika virus. J Clin Virol. 2008;43:96-101.

5. Huzly D, Hanselmann I, Schmidt-Chanasit J, Panning M. High specificity of a novel Zika virus ELISA in European patients after exposure to different flaviviruses. Euro Surveill. 2016;21(16). doi:10.2807/1560-7917.ES.2016.21.16. 30203.

6. Haddow AD, Schuh AJ, Yasuda CY, Kasper MR, Heang V, Huy R, et al. Genetic characterization of Zika virus strains: geographic expansion of the Asian lineage. PLoS Negl Trop Dis. 2012;6:e1477.

7. Gourinat AC, O'Connor O, Calvez E, Goarant C, Dupont-Rouzeyrol M. Detection of Zika virus in urine. Emerg Infect Dis. 2015;21:84-6.

8. Musso D, Roche C, Nhan TX, Robin E, Teissier A, Cao-Lormeau VM. Detection of Zika virus in saliva. J Clin Virol. 2015;68:53-5.

9. Bingham AM, Cone M, Mock V, Heberlein-Larson L, Stanek D, Blackmore C, et al. Comparison of test results for Zika virus RNA in urine, serum, and saliva specimens from persons with travel-associated Zika virus disease Florida, 2016. MMWR Morb Mortal Wkly Rep. 2016;65:475-8.

10. Bonaldo MC, Ribeiro IP, Lima NS, Dos Santos AA, Menezes LS, da Cruz SO, et al. Isolation of Infective Zika Virus from Urine and Saliva of Patients in Brazil. PLoS Negl Trop Dis. 2016;10:e0004816.

11. Barzon L, Pacenti M, Berto A, Sinigaglia A, Franchin E, Lavezzo E, et al. Isolation of infectious Zika virus from saliva and prolonged viral RNA shedding in a traveller returning from the Dominican Republic to Italy, January 2016. Euro Surveill. 2016;21:30159.

12. Peeling RW, Artsob H, Pelegrino JL, Buchy P, Cardosa MJ, Devi S, et al. Evaluation of diagnostic tests: dengue. Nat Rev Microbiol. 2010;8:S30-8.

13. Busch MP, Kleinman SH, Tobler LH, Kamel HT, Norris PJ, Walsh I, et al. Virus and antibody dynamics in acute west nile virus infection. J Infect Dis. 2008;198:984-93. 
14. Burke DS, Nisalak A, Ussery MA, Laorakpongse T, Chantavibul S. Kinetics of $\operatorname{lgM}$ and $\lg G$ responses to Japanese encephalitis virus in human serum and cerebrospinal fluid. J Infect Dis. 1985;151:1093-9.

15. Koraka P, Zeller H, Niedrig M, Osterhaus AD, Groen J. Reactivity of serum samples from patients with a flavivirus infection measured by immunofluorescence assay and ELISA. Microbes Infect. 2002:4(12):1209-15.

16. Lanciotti RS, Lambert AJ, Holodniy M, Saavedra S, Signor LC.

Phylogeny of Zika virus in Western Hemisphere, 2015. Emerg Infect Dis. 2016;22:933-5.

Submit your next manuscript to BioMed Central and we will help you at every step:

- We accept pre-submission inquiries

- Our selector tool helps you to find the most relevant journal

- We provide round the clock customer support

- Convenient online submission

- Thorough peer review

- Inclusion in PubMed and all major indexing services

- Maximum visibility for your research

Submit your manuscript at www.biomedcentral.com/submit 